\title{
NT-proBNP as a biomarker of right ventricular dilatation and pulmonary regurgitation in Tetralogy of Fallot
}

\author{
Israel Valverde ${ }^{1,2^{*}}$, Annalisa Paolino $^{1}$, Maria Pilar Serrano Gotarredona ${ }^{3}$, Silvia Navarro ${ }^{3}$, Nieves Romero ${ }^{4}$, \\ Joaquin Fernandez-Cruz ${ }^{3}$
}

From 18th Annual SCMR Scientific Sessions

Nice, France. 4-7 February 2015

\section{Background}

After surgical correction of Tetralogy of Fallot (TOF), residual pulmonary regurgitation (PR), right ventricular (RV) dilatation and RV failure have been associated with adverse clinical events and are considered criteria for pulmonary valve replacement. Cardiovascular magnetic resonance imaging (CMR) is the gold-standard for evaluation of these parameters. However it is an expensive technique which is not readily available in all hospitals and outpatient clinics. NT-proBNP is a biomarker which may overcome these CMR limitations and might be used as a cost-effective biomarker for monitoring patients with TF.

The aim of this study is to evaluate whether NTproBNP plasma levels may help as a biomarker for monitoring ventricular dilatation, pulmonary valve regurgitation and heart failure in patients with repaired TF

\section{Methods}

Single-centre observational prospective study including 40 patients $(14.3 \pm 6.7$ years, mean \pm standard deviation) with corrected TOF referred to our MRI unit. Data collection included: Clinical Parameters (electrocardiogram, chest X-ray, NYHA scale, time since last surgery), Biochemistry (NT-proBNP levels) and CMR (ventricular volumetry assessment by 2D-SSFP sequence (TR/TE $=3.0$ / $1.5 \mathrm{~ms}$, flip angle $=60^{\circ}$, resolution $1.7 \times 1.7 \times 8 \mathrm{~mm}$, SENSE $=2$ ) and aortic and pulmonary flow assessment by 2D-phase contrast flow $\left(\mathrm{TR} / \mathrm{TE}=4.4 / 2.4 \mathrm{~ms}\right.$, flip angle $=10^{\circ}$, resolution $1.5 \times 1.5 \times 8 \mathrm{~mm}$, averages $=2$ ).

${ }^{1}$ Paediatric Cardiology, Hospital Virgen del Rocio, Seville, Spain Full list of author information is available at the end of the article

\section{Results}

Mean time since last surgery was $13.1 \pm 6.3$ years. Most patients were asymptomatic (median NYHA scale 1 ), with QRS duration of $125 \pm 19 \mathrm{~ms}$ and a cardiothoracic ratio of $0.57 \pm 0.1$. The mean NT-proBNP was $175 \pm 109$ $\mathrm{ug} / \mathrm{ml}$. CMR analysis revealed a dilated indexed RV-enddiastolic-volume (RV-EDVi) of $125 \pm 32 \mathrm{ml} / \mathrm{m} 2$ and RV-end-systolic-volume (RV-ESV $\mathrm{i}_{\mathrm{i}}$ ) of $55 \pm 19 \mathrm{ml} / \mathrm{m} 2$, moderate to severe PR-fraction of $36 \pm 17 \%$ and good biventri-

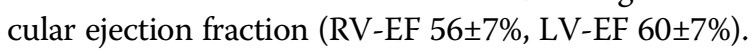

The statistical analysis showed a statistically significant correlation between the NT-proBNP and RV dilatation for both the RV-EDV (Pearson 0.54, $\mathrm{p}<0.01$ ) and RVESV $_{\mathrm{i}}$ (Pearson 0.52, $\mathrm{p}<0.01$ ) and also with the PR fraction (Pearson $0.26, \mathrm{p}<0.01$ ). There was no statistically significance found between NT-proBNP and RV-EF (Pearson=0.26), LV-EF (Pearson 0.24 ) or any clinical parameters.

The receiver operating curve analysis evidenced that a NT-proBNP cut-off value above $145 \mathrm{pg} / \mathrm{ml}$ predicts the presence RV-EDV ${ }_{\mathrm{i}}$ dilatation over over percentile 95 [1] (Sensitivity $71 \%$, specificity $100 \%$ ), RV-ESV $\mathrm{V}_{\mathrm{i}}$ dilatation over percentile $95^{1}$ (Sensitivity $88 \%$, Specificity $89 \%$ ) and severe PR $>40 \%$ (Sensitivity $72 \%$, Specificity $73 \%$ ).

\section{Conclusions}

In patients with surgically corrected TOF, NT-proBNP levels correlate with RV dilatation and the degree of pulmonary regurgitation. Ambulatory determination of NT-proBNP might be an easy, readily available and cost-effective alternative for follow-up evaluation of these patients and may help decide when to request an MRI study for follow-up evaluation 

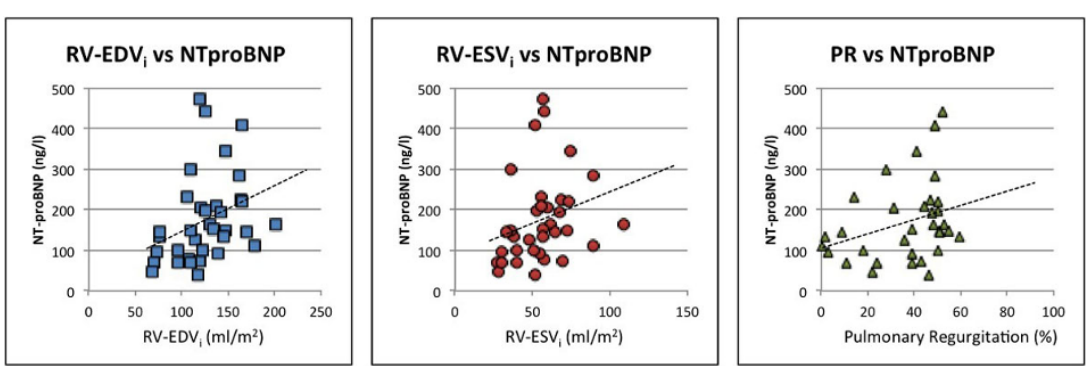

Figure 1

\section{Funding}

N/A.

\section{Authors' details}

${ }^{1}$ Paediatric Cardiology, Hospital Virgen del Rocio, Seville, Spain.

${ }^{2}$ Cardiovascular Pathology Unit, Institute of Biomedicine of Seville (IBIS),

Seville, Spain. ${ }^{3}$ Radiology, Hospital Virgen del Rocio, Seville, Spain.

${ }^{4}$ Cardiology, Hospital Virgen del Rocio, Seville, Spain.

Published: 3 February 2015

\section{Reference}

1. Valsangiacomo $E$, et al: JCMR 2009, 11:19.

doi:10.1186/1532-429X-17-S1-Q100

Cite this article as: Valverde et al:: NT-proBNP as a biomarker of right

ventricular dilatation and pulmonary regurgitation in Tetralogy of Fallot.

Journal of Cardiovascular Magnetic Resonance 2015 17(Suppl 1):Q100.

Submit your next manuscript to BioMed Central and take full advantage of:

- Convenient online submission

- Thorough peer review

- No space constraints or color figure charges

- Immediate publication on acceptance

- Inclusion in PubMed, CAS, Scopus and Google Scholar

- Research which is freely available for redistribution

Submit your manuscript at www.biomedcentral.com/submit 